\title{
Analyses of Supercontinuum Generation in Photonic Crystal Fibers
}

https://doi.org/10.32792/utq/utj/vol11/4/4

\section{Noora Hussain Ali , Hassan Abid Yasser \\ Thi-Qar University, College of Science, Physics Department \\ nooralhussain574@yahoo.com}

\begin{abstract}
In this work, the solid PCF are studied, where the solid core was surrounded by a number of holes with a diameter $d$ away from each other by $\Lambda$ distance. The strange behavior of dispersion with the presence of nonlinear phenomenon such as: self-phase modulation, self-steepening and stimulated Raman scattering allows the formation of higher order solitons in a short distance range $(1-2) \mathrm{cm}$. The study of SCG has been done by the numerical solution for the generalized propagation equation, where the Fourier transform method is used to solve the linear part and Runge-Kutta method to solve the nonlinear part. Higher order soliton means the possibility of soliton fission to the fundamental solitons and emissions the dispersive wave, this means the formation SCG. The SCG has been affected by each of: width, power and wavelength of the input pulses. On the other side, it is also affected by the fiber parameters $d$ and $\Lambda$ that in turn controls the zero dispersion wavelength $\lambda_{0}$, where the conditions $\left(\lambda_{0}<\lambda\right)$ and $\left(\lambda_{0}>\lambda\right)$ form bright soliton and dark soliton, respectively.
\end{abstract}

Keywords: Supercontinuum Generation, Photonic Crystal Fiber, Dispersion, Stimulated Raman Scattering, Self-Steepening.

\section{Introduction}

Supercontinuum generation (SCG) is the formation of broad continuous spectra by propagation of high power pulses through nonlinear media, and was first observed in 1970 by Alfano and Shaparo [1]. The term supercontinuum (SC) does not cover a specific phenomenon but rather a plethora of nonlinear effects, which, in combination lead to extreme pulse broadening. The generation of white laser in terms of $\mathrm{SC}$ is an important phenomenon having great physical implications. It certainly offers novel solutions in the field of optical communication, coherent 


\section{University of Thi-Qar Journal Vol.11 No.4 DEC 2016}

Web Site: https://jutq.utq.edu.iq/index.php/main Email: journal@jutq.utq.edu.iq

tomography, multiplex light sources for nonlinear spectroscopy, biomedical lasers, etc.. The mechanism of SC generation is mainly dominated by soliton dynamics when a femtosecond pulse is used as a pump, where four wave mixing (FWM) and nonlinear Kerr effect are considered to be the most important processes in SC generation for wider (pico or nanosecond) input pulses. In both the cases, higherorder dispersions (HODs) play a significant role in modulating and controlling the spectrum [2].

In recent years, photonic crystal fibers (PCFs) are considered to be the most effective medium for SCG because of its high nonlinearity and flexible dispersion properties [2]. PCFs generally consist of solid core with air-holes arranged in general triangular lattice format along the axis of core [3]. The dimensions of the photonic crystal cladding are described using the hole-to-hole spacing, or pitch $(\Lambda)$, and the hole diameter (d) as shown in Fig.(1). By changing the pitch and hole size, the dispersion and nonlinearity can be changed. The number of rings of air holes in the cladding is also an important quantity, impacting on confinement loss [4]. Usually PCFs are fabricated from silica, with an array of air holes in the cladding, which run the entire length of the fiber. Alternatively, doped silica rods can be used instead of air, or the air holes can be filled after fabrication with liquid or gas. PCFs can be split into two main groups - index guiding PCF and band gap guiding PCF. Index guiding PCF have a solid core, which is a defect in the air-hole array, or in other words, a missing hole [5]. Guidance in solid-core PCF occurs in a similar way to total internal reflection in conventional fibers. The effective refractive index of the air hole lattice in the cladding is lower than the refractive index of the core material, and so guidance occurs via "modified total internal reflection" [5]. On the other hand, hollow-core photonic crystal has an air hole in the core region and transmits light by photonic bandgap type guidance. PCFs have been under intensive study as they offer design flexibility in controlling the modal properties [6].

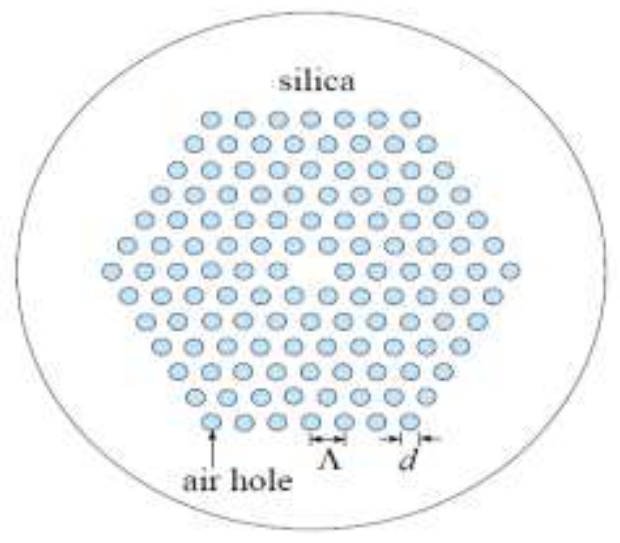




\section{University of Thi-Qar Journal Vol.11 No.4 DEC 2016}

Web Site: https://jutq.utq.edu.iq/index.php/main Email: journal@jutq.utq.edu.iq

Fig.(2.5): Schematic representation of PCF [7].

In this paper, the generalized nonlinear Schrödinger equation (GNLSE) that describes the evolution of signal in the single mode has been derived. The derivation depends strongly on the Kerr and Raman susceptibilities. So, these susceptibilities are also analyzed in details. The physical mechanisms of SCG are presented to explain the behavior of the propagated signals. The dispersion parameters will extracted depending on the effective propagation constant and the effective refractive index. Finally, the GNLSE will be solved numerically using the split-step Fourier method (SSFM).

\section{Generalized Propagation Equation}

The wave equation is the basis of the optical pulses propagation through of the optical fibers derived from Maxwell equations. The differential equation for propagation of optical pulses through PCFs for single mode fiber that named as general nonlinear Schrödinger equation (GNLSE) written in it normalized form as [8]

$$
\overbrace{\frac{\partial U}{\partial \xi}+\frac{\alpha L_{D}}{2} U-j \sum_{m=2}^{\infty} j^{m} \delta_{m} \frac{\partial^{m} U}{\partial \tau^{m}}}^{\text {Linear effect }}=\overbrace{j N^{2}(\underbrace{\left.U\right|^{2} U}_{S P M}+\underbrace{j S \frac{\partial}{\partial \tau}\left(|U|^{2} U\right)}_{\text {self -steepening }}-\underbrace{\tau_{R} U \frac{\partial|U|^{2}}{\partial \tau}}_{\text {Raman effect }})}^{\text {nonlinear effect }}
$$

where $U(\xi, \tau)$ is the normalized amplitude number and the other dimensionless variables are defined as [9]

$$
\tau=\frac{t-z / v_{g}}{T_{0}}, \xi=\frac{z}{L_{D}}, N^{2}=\gamma P_{0} L_{D}, \quad \tau_{R}=\frac{T_{R}}{T_{0}}, \delta_{m}=\frac{\beta_{m}\left(w_{0}\right)}{m !\left|\beta_{2}\left(w_{0}\right)\right| T_{0}^{m-1}}
$$

Here $T_{0}$ is a measure of the pulse width at half maximum, $P_{0}$ is the peak value power of initial pulse, $\gamma$ the nonlinear coefficient, $L_{D}=T_{0}^{2} /\left|\beta_{2}\left(w_{0}\right)\right|$ is the dispersion length where $\beta_{2}$ is second order dispersion coefficient, $S=\left(w_{0} T_{0}\right)^{-1}$ is the self-steepening (SS) parameter and $N$ is called the soliton order.

\section{Dispersion Managements}

The fully vector finite element method (FEM) has been applied to PCF modeling successfully. It allows calculating both dispersion and losses for both PBG and solid core structure. For a given frequency, the method provides us with a complex propagation constant $\beta=\operatorname{Re}\{\beta\}+i \operatorname{Im}\{\beta\}$, where $\operatorname{Re}\{\beta\}$ is the 


\section{University of Thi-Qar Journal Vol.11 No.4 DEC 2016}

Web Site: https://jutq.utq.edu.iq/index.php/main Email: journal@jutq.utq.edu.iq

standard propagation constant of the wave along the fiber and $\operatorname{Im}\{\beta\}$ is the attenuation constant associated with the exponential decay along the fiber axis [10]. Both the effective cladding index and the effective index of the guided mode of the PCF are calculated using the solution of Maxwell equations in the infinite two dimensional photonic crystal structure, when the modal index of fundamental space filling mode index $n_{F S M}$ may be determined [11]. In order to calculate $n_{F S M}$ for the PCF, the hexagonal unit cell, Fig.(2), is approximated by a circular one of radius $R$.

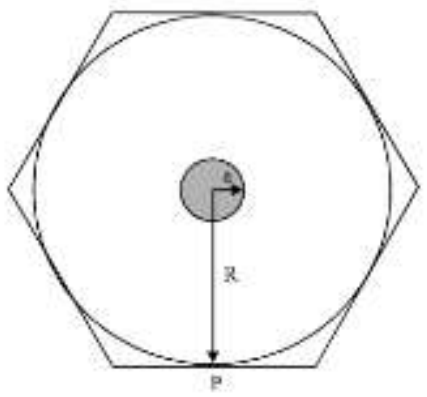

Fig.(2): The hexagonal unit cell and its circular equivalent [11].

At a point $P$ on the boundary, $\psi$ and $\partial \psi / \partial n$ should be continuous at the interface, when $\hat{n}$ is outward unit vector normal to the boundary. The electric field component $E$ of the fundamental mode in the corresponding regions is [12]

$$
E= \begin{cases}\frac{E_{0} J_{0}(U r / a)}{J_{0}(U)} & r \leq a \\ \frac{E_{0} K_{0}(W r / a)}{K_{0}(W)} & r>a\end{cases}
$$

where $a$ is air-hole radius, $r$ is cylindrical parameter and the characteristic equation has the form [12]

$$
\frac{J_{0}(U)}{U J_{1}(U)}=\frac{K_{0}(W)}{W K_{1}(W)}
$$

where $J_{0}, J_{1}$, and $K_{0}, K_{1}$ are zero and first order Bessel functions and modified Bessel functions, respectively. The parameters $U$ and $W$ are defined as [12]

$$
\begin{aligned}
& U=k_{0} a \sqrt{n_{1}^{2}-n_{e f f}^{2}} \\
& W=k_{0} a \sqrt{n_{e f f}^{2}-n_{F S M}^{2}}
\end{aligned}
$$

Summing the parameters $U^{2}$ and $W^{2}$, yields 


\section{University of Thi-Qar Journal Vol.11 No.4 DEC 2016}

Web Site: https://jutq.utq.edu.iq/index.php/main Email: journal@jutq.utq.edu.iq

$$
V=\sqrt{U^{2}+W^{2}}=k_{0} a \sqrt{n_{1}^{2}-n_{F S M}^{2}}
$$

where $U$ and $W$ are called, respectively, the normalized transverse phase and attenuation constant. The normalized frequency $V$ may be determined the number of modes that will propagate through PCF. Note that, $n_{\text {eff }}$ represents effective index of guided mode that satisfies the condition [13]

$$
n_{1}>n_{\text {eff }}>n_{F S M}
$$

where $\beta$ is the mode propagation constant, $n_{\text {eff }}$ is the core index, and $n_{F S M}$ is the cladding effective index, which is termed also the effective index of the fundamental space-filling mode (FSM). However, the solution of Eq.(5) and (6) may be obtained the values of $U, V$ and $W$ for the fundamental mode. In turn, the $n_{F S M}$ and $n_{\text {eff }}$ may be explained.

The definition at $V$ is intrinsically different from the original $V$ definition in step index fiber. Although the $V$ parameter offers a simple way to design a PCF, a limiting factor for using Eq.(6) is that a numerical method is still required for obtaining the effective cladding index $n_{F S M}$. In analogy with expressions for standard fibers it would then for be convenient to have an alternative expression only dependent on wavelength $\lambda$ and the structural parameters $d$ and $\Lambda$. By trial and error, Saitoh and Koshiba [7] are proved that the $V$ parameter can be approximated as a function of the parameters $\lambda, \Lambda$ and $d$ as follows

$$
V=A_{1}+\frac{A_{2}}{1+A_{3} e^{A_{4}(\lambda / \Lambda)}}
$$

where the parameters $A_{i}$ are defined as $A_{i}=\sum_{j=0}^{3} a_{i j}(d / \Lambda)^{b i j}$ and the coefficients $a_{i j}$ and $b_{i j}$ are given in Ref.[7]. Using the effective $V$ parameter in Eq.(8), the effective index $n_{F S M}$ can be obtained without the need for numerical computations. Depending on the above manganite, the determination of $n_{\text {eff }}$ will also require heavy numerical computations. It would be more convenient to have on empirical relation for the $W$ parameter of PCFs. Nielsen et al [7] have reported the empirical relation for the $W$. However, one cannot obtain the value of $n_{\text {eff }}$ from the $W$ parameter only. In order to obtain $n_{\text {eff }}$, we need the empirical relation for both $V$ and $W$ parameters. The suggested relation of $W$ was as follows [11] 


\section{University of Thi-Qar Journal Vol.11 No.4 DEC 2016}

Web Site: https://jutq.utq.edu.iq/index.php/main Email: journal@jutq.utq.edu.iq

$$
W=B_{1}+\frac{B_{2}}{1+B_{3} e^{B_{4}(\lambda / \Lambda)}}
$$

where the constants $B_{i}$ are defined as $B_{i}=\sum_{j=0}^{3} c_{i j}(d / \Lambda)^{d_{i j}}$ and the coefficients $c_{i j}$ and $d_{i j}$ are given in Ref.[11]. For each $\lambda / \Lambda$ and $d / \Lambda$, the parameters $V, W$ may be calculated. In turn, Eqs.(5) and (6) may be reformed to get [14]

$$
n_{\text {eff }}=\sqrt{n_{1}^{2}-\left(\frac{1}{k_{0} a}\right)^{2}\left(V^{2}-W^{2}\right)}
$$

The real part of $n_{\text {eff }}$ satisfies the property $n_{1}>\operatorname{Re}\left\{n_{\text {eff }}\right\}>n_{F S M}$.

The PCF have some extraordinary properties, such that wide single mode wavelength range, unusual chromatic dispersion, and low or high nonlinearity. Chromatic dispersion plays an important role in the performance of a highly nonlinear fiber, as it directly affects pulse broadening, phase-matching conditions, in order to determine the bandwidth and power requirement of the device in which the fiber will be used. Dispersion can be varied by changing air hole diameter and pitch sizes of the PCF. The total dispersion is the sum of material dispersion and waveguide dispersion. Control of the chromatic dispersion in PCFs is one of the most critical problems in optical communication systems. The waveguide dispersion of PCFs is easily calculated from the value of the $n_{\text {eff }}$ as follows [15]

$$
D_{w}(\lambda)=-\frac{\lambda}{c} \frac{d^{2} \operatorname{Re}\left\{n_{e f f}\right\}}{d \lambda^{2}}
$$

According to this equation, the waveguide dispersion is calculated from the second derivative of the effective index with respect to wavelength. The parameters $d$ and $\Lambda$ are used to control this type of dispersion at a range of wavelengths. The material dispersion is defined as [16]

$$
D_{m}(\lambda)=-\frac{\lambda}{c} \frac{\partial^{2} n_{1}}{\partial \lambda^{2}}
$$

where $n_{1}$ is the refraction index of the silica glass as a function of wavelength (normally calculated from the Sellmeier equation), which is defined as [17]

$$
n^{2}(\lambda)=1+\sum_{i=1}^{3} \frac{A_{j} \lambda^{2}}{\lambda^{2}-\lambda_{j}^{2}}
$$




\section{University of Thi-Qar Journal Vol.11 No.4 DEC 2016}

Web Site: https://jutq.utq.edu.iq/index.php/main Email: journal@jutq.utq.edu.iq

where $\lambda_{j}$ and $A_{j}$ are the $j t h$ resonant wavelength and strength. Eqs.(11) and (12) may combined and reformed to explain

$$
D=D_{m}+D_{w}=-\frac{\lambda}{c} \frac{\partial^{2}\left(\operatorname{Re}\left\{n_{\text {eff }}\right\}+n_{1}\right)}{\partial \lambda^{2}}
$$

The dispersion effect in PCF is related to the Taylor series of mode propagation constant around the center frequency $w_{0}[14]$

$$
\beta(w)=n_{e f f}(w) \frac{w}{c}=\beta_{0}+\beta_{1}\left(w-w_{0}\right)+\frac{1}{2} \beta_{2}\left(w-w_{0}\right)^{2}+\ldots
$$

where $c$ is speed of light, $\beta_{k}$ is $k t h$ dispersion coefficient expressed by

$$
\beta_{k}=\left(\frac{\partial^{k} \beta(w)}{\partial w^{k}}\right)_{w=w_{0}}
$$

The second dispersion coefficient $\beta_{2}$ accounts for the group velocity dispersion (GVD), which GVD is defined as the change in pulse width per unit distance of propagation, which is [14]

$$
\beta_{2}=-\frac{\lambda^{2}}{2 \pi c} D(\lambda)
$$

The different order of dispersions may be found using Eq.(17) according to the selected number of Taylor expansion. Note that, the refractive index $n_{\text {eff }}$ is a function of $d, \Lambda$ and $\lambda$. Consequently, the total dispersion may be formed to satisfy the required properties of the different order parameters of dispersion.

\section{Results and Discussion}

In PCF the phenomenon SCG is caused by a number of nonlinear phenomena such as SS, SRS, and SPM and linear such as dispersion of various orders. The different dispersion orders can be controlled in this type of optical fibers in order to maximize the occurrence of the phenomenon SGG. For this, the empirical relationships Eqs.(8) and (9) are used to calculate the Parameters $W, V$ that depend on properties of the fiber used by controlling $d, \Lambda, \lambda$ on consideration that diameter core will be equal $\sqrt{3} \Lambda$. As a result, it has been using Eq.(10) to calculate $n_{\text {eff }}$, which is an important and essential factor to calculate through the application of Eq.(11). 


\section{University of Thi-Qar Journal Vol.11 No.4 DEC 2016}

Web Site: https://jutq.utq.edu.iq/index.php/main Email: journal@jutq.utq.edu.iq

In the next step, the generalized propagation equation, Eq.(1) will be solved. Which includes two steps; the use of Fourier transform and numerical solution by using the Runge-Kutta of the fourth order with the knowing that input pulse according to $T_{0}=T_{F W H M} / 1.76$ where $T_{F W H M}$ is the half maximum pulse width. It must be noted here that the above numerical method based on the dividing of an optical fiber into small parts length $\Delta z$.The results must be recursively after each until section they reach the end of the optical fiber. On the other hand, the Fourier transform depends on the division of space time into small parts $\Delta \tau$. The accuracy of the results depends on the correct choice of each $\Delta z, \Delta \tau$. Incompleteness is not necessarily because it related to the addition of error due to truncation and running.

Fig.(3) represents $n_{\text {eff }}, D_{t o t}, \beta$ 's as functions of wavelength using $\Lambda=1.4 \mu m, \quad d=(0.8: 0.2: 1.2) \mu m$. The first figure in the upper left corner represents the refractive index as a function of wavelength where the continues line indicates $n_{1}$, while other lines refers to $n_{\text {eff }}$ with different values of $d$. One can note from this figure that the increasing of diameter hole will change the refractive index profile and the change will greatest in the event increased $d$ to the value of close to $\Lambda$, but this value $d$ cannot be greater than that because the empirical relation that have been adopted does not allow it. This acceptable physically because increase hole numbers means the presence of a decrease in air-filling fraction (AFF); thus a change in the refractive index. The relation of $D$ with $\lambda$ shows the change of $D$ with different values of $d$ as long as $D$ based on the second derivative for coefficient $n_{\text {eff }}$. This means the possibility of dispersion balancing by controlling $d$ and $\Lambda$. Increase of $d$ doesn't mean necessarily the deflection of curves to a certain side, but that could change shape of the curve shows more than values of $\lambda_{0}$.

All other subfigure in Fig.(3) represent $\beta^{\prime} s$ as functions of $\lambda$. The $\beta_{2}$ may be equal to zero depending on $d$ value, this means that $\lambda_{0}$ of the fiber used will vary from case to case, where the case $D>0$ happen at $\lambda>\lambda_{0}$, this system called anomalous dispersion and at the case $D<0$ for $\lambda<\lambda_{0}$, this system called normal dispersion.

To construct the SCG, the work is always in the region $\lambda>\lambda_{0}$ for physical necessities that have been clarified already. Note that, the curves will be distinct for different $d$ situations that will be different after $0.9 \mu \mathrm{m}$, it means that $\beta$ 's will be important in the region far away from that. Accordingly, the SCG will become more distinct in this range. 


\section{University of Thi-Qar Journal Vol.11 No.4 DEC 2016}

Web Site: https://jutq.utq.edu.iq/index.php/main Email: journal@jutq.utq.edu.iq

Fig.(4) represents the spectral evolution in the distance $5 \mathrm{~cm}$ of PCF of the simulations of SCG with various input power values $P_{0}$ when $T_{0}=30 \mathrm{fs}, \lambda=960 \mathrm{~nm}$ using dispersion coefficients which are calculated using the $d=1 \mu \mathrm{m}, \Lambda=1.4 \mu \mathrm{m}$ which gives $\lambda_{0}=865 \mathrm{~nm}$. If we look at the cases of Fig.(3), they represent the presence of: SRS and $\beta^{\prime} s$ and SRS and $\beta_{2}$, respectively.

In Fig.(4a) we notice that the spectrum band is very narrow with little power (corresponding small order soliton). The fact that $P_{0}$ small makes $L_{N L}$ large and thus the band remain narrow. With the increasing of $P_{0}$, the $L_{N L}$ will be lower and the corresponding will be raised in soliton order. Compatibility of this increase with a decrease in the length of fission $L_{\text {fiss }}$, and therefore note that a spectral width is increasing and may reach more than $700 \mathrm{~nm}$. In case $N=1.4$ means that the order soliton is not integer number and the pulse tends to rise to an integer of $N$ that is the fundamental soliton which it does not appear any change during the propagation. Increasing of $N$ means generation of perturbed soliton because of the presence SRS, SS and higher order dispersion. This leads to soliton fission to fundamental solitons and this leads to increase the width of the resulting spectrum

Fig.(4b) shows the results by neglecting the higher order dispersion. Here we note that context of the spectral shape being destroyed and will not be undergo to the same interpretations above expect for a situation for a small input power. Here we cannot say that the spectrum generated here represents a SCG because of the phenomena that caused this spectrum did not appear.

Fig.(5) represents the time evolution in the distance $5 \mathrm{~cm}$ to PCF simulate SCG using the same coefficients used in the Fig.(4). Cases of Fig.(5) represents the presence of: SRS and $\beta^{\prime} s$ and SRS and $\beta_{2}$, respectively. Here we note from the figure that the resulting pulse will not suffer from the fissions when ignore the higher dispersion effects for all the input power values. Lastly, the neglect of the dispersion effects will maintain the pulse shape to a large extend for the propagation without change except only some minor fissions with increase the amount of input power. In the case of presence higher dispersion effects, the fission soliton will be clear with increase the amount of input power. The presence of SRS with effects $\beta^{\prime} s$ will lowered these fissions to a certain amount. The broadening temporal is corresponding to the spectral broadening in Fig.(4) but the spectral broadening in Fig.(5b) is not corresponding by a temporal broadening in Fig.(5) due to the generated broadening is not connect to the issue of soliton fission, but it is the result of a segments in the shape of pulses (generate narrow secondary pulses) corresponding by a broad spectrum who did not get the so called SCG. The presence 


\section{University of Thi-Qar Journal Vol.11 No.4 DEC 2016}

Web Site: https://jutq.utq.edu.iq/index.php/main Email: journal@jutq.utq.edu.iq

of SRS causes the controlling of the displacements of the pulse and thus the resulting. Work with the higher dispersion effects may lead to improve or reduce the width of the temporal evolution of the pulse according to the other surrounding properties such as the power and pulse width, etc..
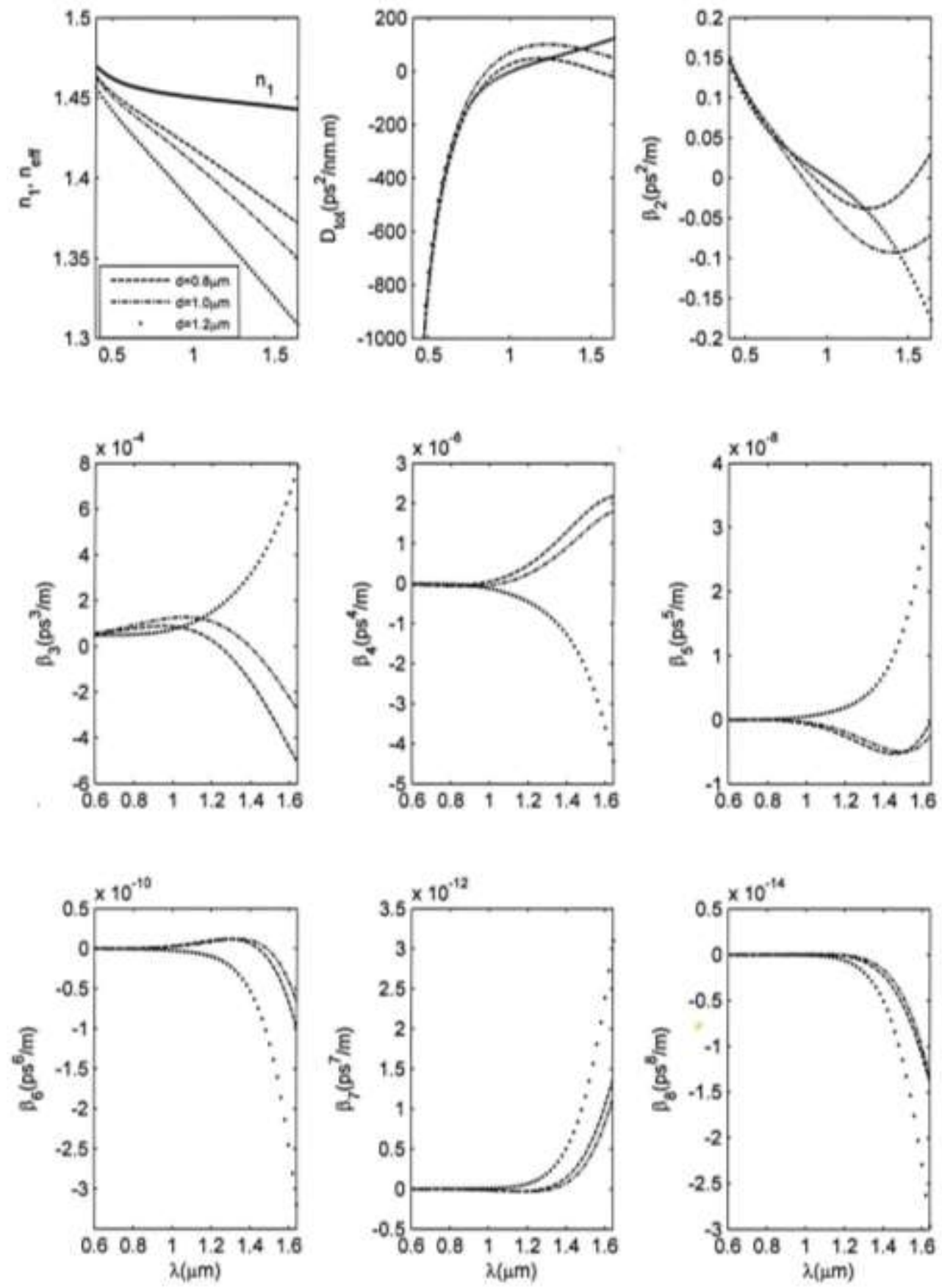


\section{University of Thi-Qar Journal Vol.11 No.4 DEC 2016}

Web Site: https://jutq.utq.edu.iq/index.php/main Email: journal@jutq.utq.edu.iq

Fig.(3): $n_{\text {eff }}, D_{t o t}, \beta^{\prime} s$ as functions of wavelength using

$$
\Lambda=1.4 \mu m \text { and } d=(0.8: 0.2: 1.2) \mu m .
$$

(a): With $\beta^{\prime} s$ and SRS.
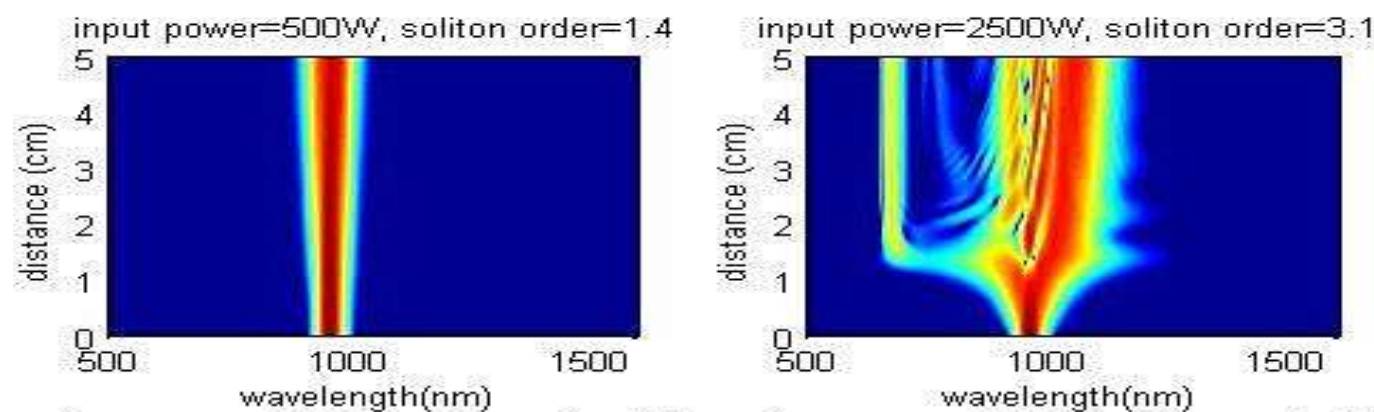

input power $=4500 \mathrm{~W}$, soliton order $=4.2$
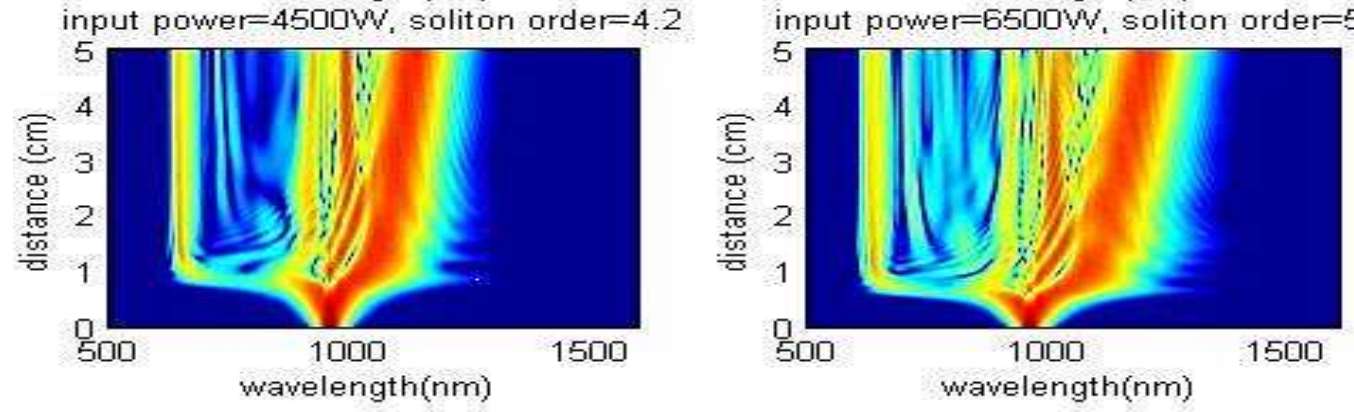

(b): With $\beta_{2}$ and SRS. 


\section{University of Thi-Qar Journal Vol.11 No.4 DEC 2016}

Web Site: https://jutq.utq.edu.iq/index.php/main Email: journal@jutq.utq.edu.iq
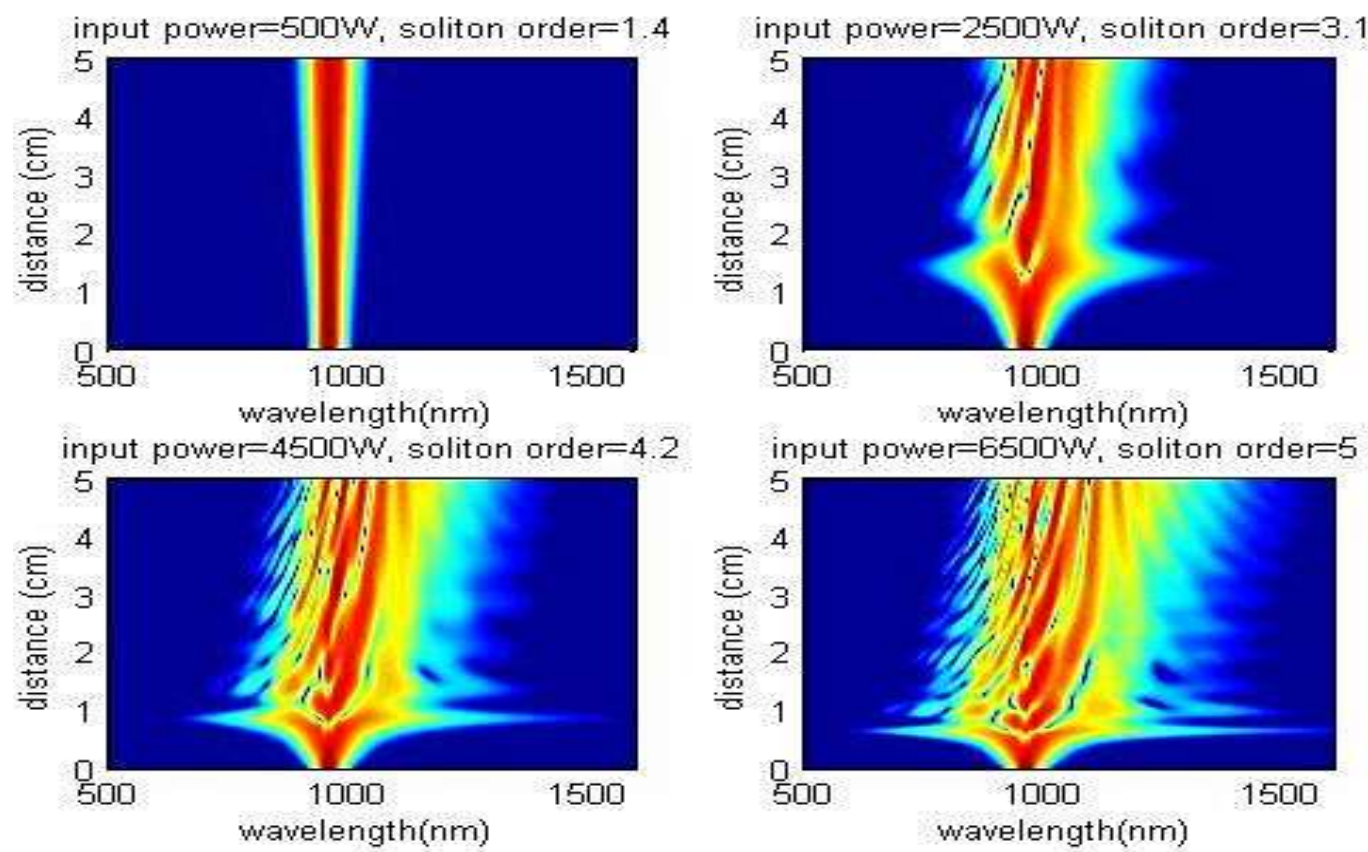

Fig.(4): Spectral evolution with different value of input power as function of $L$, where $T_{0}=30 \mathrm{fs}, \lambda=960 \mathrm{~nm}$.

(a): With $\beta^{\prime} s$ and SRS.
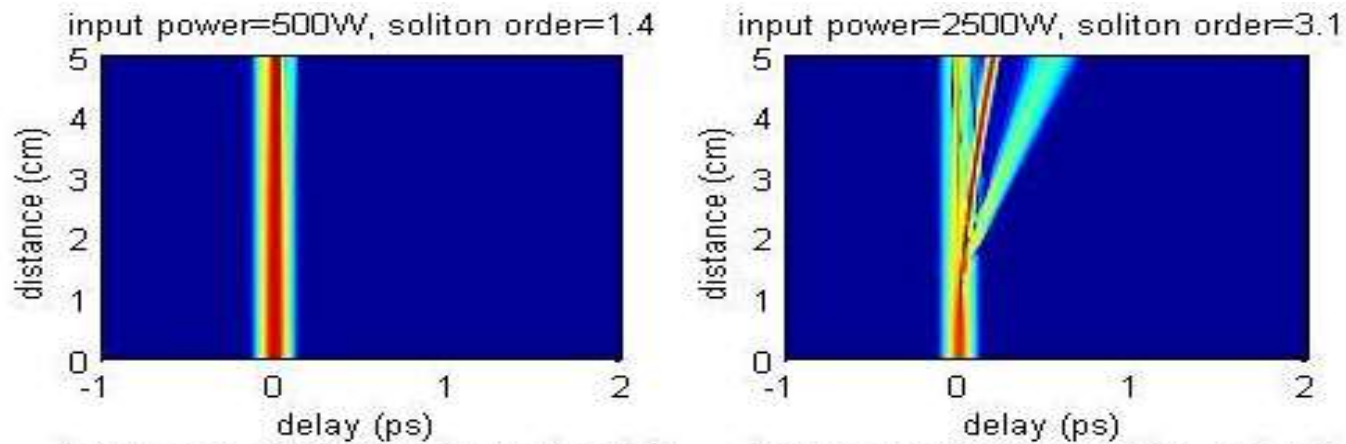

input power $=4500 \mathrm{~W}$, soliton order $=4.2$
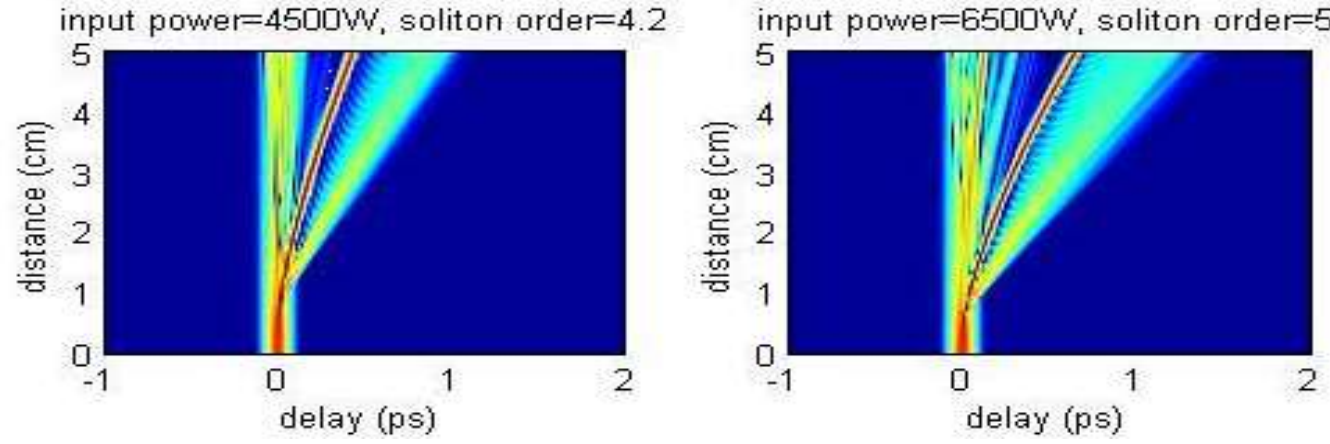


\section{University of Thi-Qar Journal Vol.11 No.4 DEC 2016}

Web Site: https://jutq.utq.edu.iq/index.php/main Email: journal@jutq.utq.edu.iq

(b): With $\beta_{2}$ and SRS.
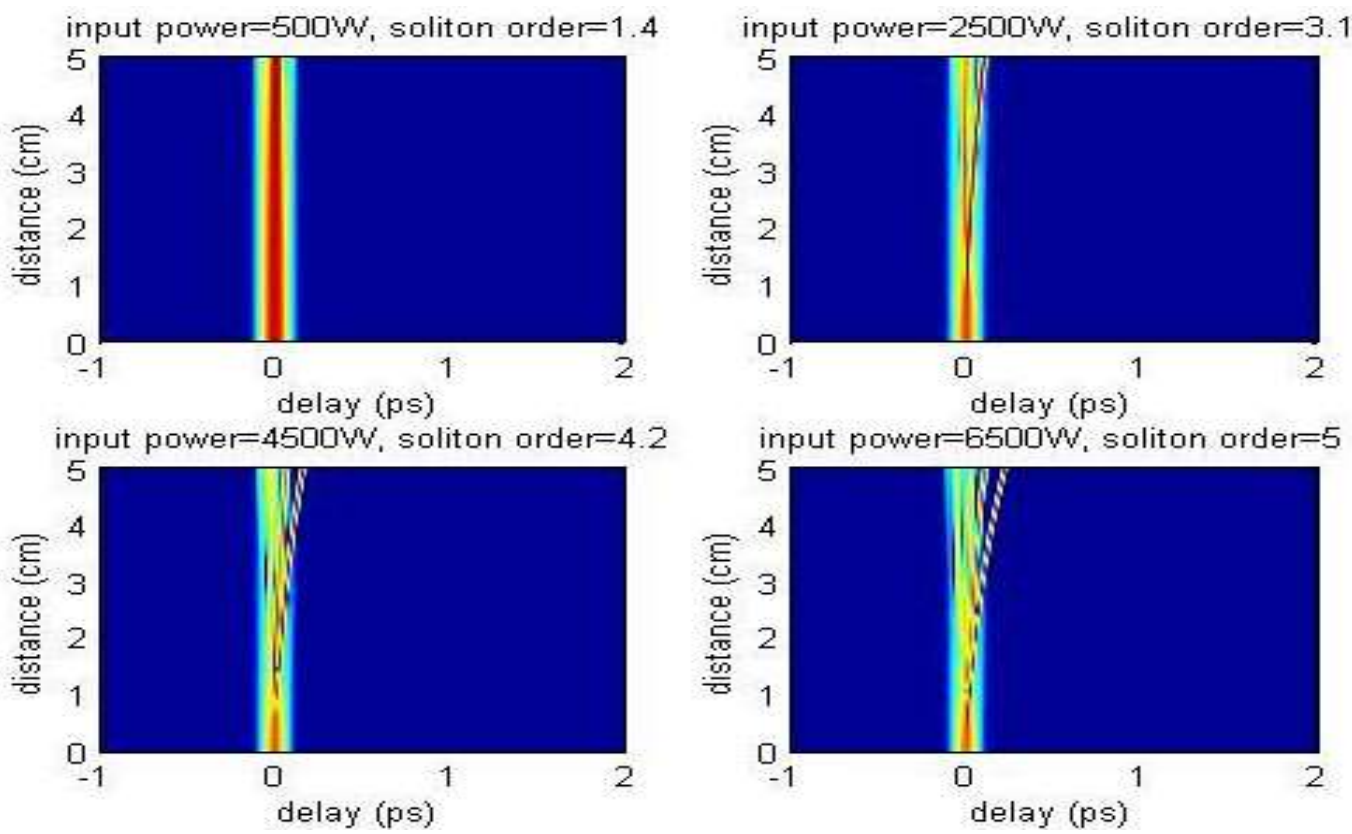

Fig.(5): Spectral evolution with different value of input power as function of $L$, where

$$
T_{0}=30 f s, \lambda=960 \mathrm{~nm} \text {. }
$$

\section{Conclusion}

In conclusion, the different dispersion orders may be formed by controlling the parameters $d$ and $\Lambda$. In turn, the SCG will be formed by controlling these parameters. The wavelength of the input signal must be $\lambda>\lambda_{0}$ in order to construct the dark soliton that causes the broad SCG. The SCG may be enhanced by increasing the fiber length or increasing the power of input signal. 


\section{University of Thi-Qar Journal Vol.11 No.4 DEC 2016}

Web Site: https://jutq.utq.edu.iq/index.php/main Email: journal@jutq.utq.edu.iq

\section{References}

1. Alfano R. and Shapiro S., "Direct Distortion of Electronic Clouds of RareGas Atoms in Intense Electric Fields,” Phys. Rev. Lett. Vol.24, No.22, pp.1217-1220, 1970.

2. Roy S., Bhadra Sh., Agrawal G., "Dispersive Wave Generation in Supercontinuum Process Inside Nonlinear Microstructured Fiber", Current Science, Vol. 100, No. 3, pp.321-342, 2011.

3. Karmakar A., Roy I. and Deyasi A., "V-Parameter Study of Silica-Air 1D Photonic Crystal Fiber by Modulating Geometrical Parameters at Different Optical Communication Ranges", Bonfring International J. Research in Communication Engineering, Vol. 2, No. 3, pp. 1-4, 2012.

4. Mangan B., Muir A. and Knight J. "Photonic Bandgap Fiber with Multiple Hollow Cores". J. Lightwave Technology, Vol. 28, No. 9, pp. 1287-1290, 2010.

5. Senior J., "Optical Fiber Communications, Principles and practice", $3^{\text {rd }}$ edition, FT Prentice Hall, 2009.

6. Abdullah A., "Laser Field Distribution in Photonic Crystal Fiber with Triple Zero Dispersion Wavelengths", J.Edu. \& Sci., Vol. 24, No.3, pp.119-132, 2011.

7. Saitoh K. and Koshiba M., "Empirical Relations for Simple Design of Photonic Crystal Fibers", Optics Express 267, Vol. 13, No.1, 2005.

8. Agrawal G., "Nonlinear Fiber Optics", $4^{\text {th }}$ edition, Academic Press, 2007.

9. Dudley J., Genty G. and Coen S., "Supercontinuum Generation in Photonic Crystal Fiber", Reviews of Modern Physics, Vol.78, No. 4, pp.1135-1184, 2006.

10. Buczynski R., "Photonic Crystal Fibers", ACTA Physic Polonia, Vol. 106, No. 2, 2004.

11. Pourkazemi A., Mansourabadi M. and Baratvand H., "Comparison between Modified Fully Vectorial Effective Index Method and Empirical Relations 


\section{University of Thi-Qar Journal Vol.11 No.4 DEC 2016}

Web Site: https://jutq.utq.edu.iq/index.php/main Email: journal@jutq.utq.edu.iq

Method for Study of Photonic Crystal Fibers", J. Applied Sciences, Vol. 10, No. 20, pp.2463-2463, 2010.

12. Karimi M. and Seraji F., "Effects of Geometry on Amplification Property of Erbium Doped Holey Fiber Amplifiers Using Scalar Effective Index Method", Progress in Electromagnetics Research B, Vol.19, pp.385-403, 2010.

13. Garcia A., Sukhoivanor I., Lucio J., Manzano O., Guryev I. and Garcia J., "Numerical Study of Highly Nonlinear Photonic Crystal Fiber with Tunable Zero Dispersion Wavelength", J. Electromagnetic Analysis and Applications, Vol. 7, No. 5, pp.141-151, 2015.

14. Zhao-lun L., Lan-tian H., Wei W., "Tailoring Nonlinearity and Dispersion of Photonic Crystal Fibers Using Hybrid Cladding", Brazilian J. Physics, Vol. 39, No. 1, pp. 50-54, 2009.

15. Nair A., Sudheer S. and Jayaraju M., "Analysis of Optical Characteristics for Photonic Crystal Fiber at Small Core Diameters", IJEAT, Vol.3, No. 4, 2014.

16. Dudley J. and Taylor R., "Supercontinuum Generation in Optical Fibers", Cambridge University Press, 2010.

17. Hsu J., Yao Ch., Chuang W., "Enhancing Approach DispersionCompensation for Dual-Concentric-Core Photonic Crystal fibers", J. Pure \&Applied Physics, Vol.53, No. , pp. 93-97, 2015. 


\section{University of Thi-Qar Journal Vol.11 No.4 DEC 2016}

Web Site: https://jutq.utq.edu.iq/index.php/main Email: journal@jutq.utq.edu.iq

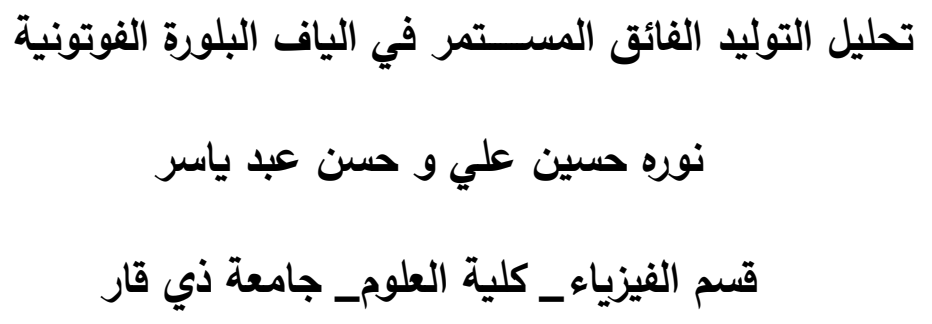

(الملخص

في هذا البحث تم دراسة الياف البلورة الفوتونية الصلبة حيث يحاط القلب الصلب بعدد من

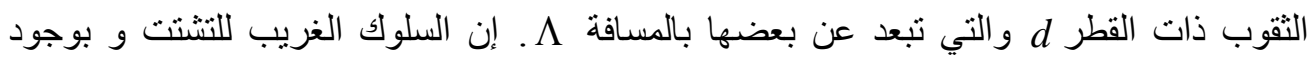

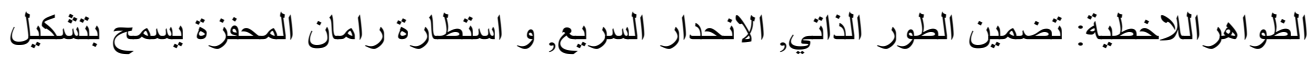

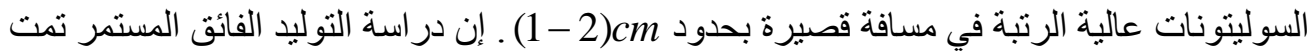
عن طريق الحل العددي لمعادلة الانتثار العامة باستخدام تحويل فورير للقسم الخطي و رانج-كوتا

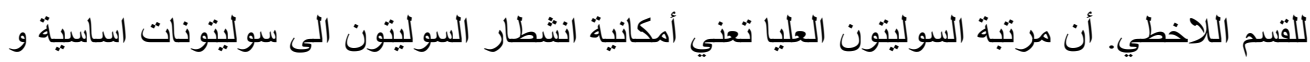

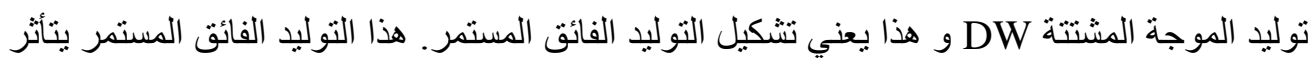

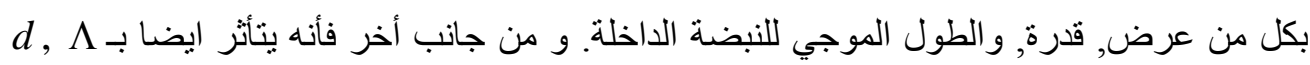

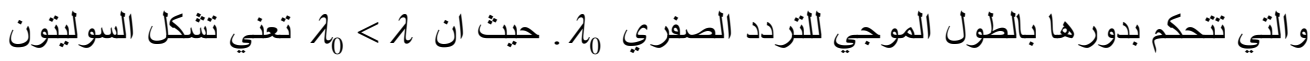
المضيء و أن $>$ أن $\lambda_{0}$ تعني تشكل السوليتون المظلم. 